\title{
A internacionalização da saúde: elementos contextuais e marcos institucionais da cooperação brasileira
}

\author{
Fernando A. Pires-Alves, ${ }^{1}$ Carlos Henrique Assunção Paiva ${ }^{1}$ \\ e José Paranaguá de Santana²
}

Como citar Pires-Alves FA, Paiva CHA, Santana JP. A internacionalização da saúde: elementos contextuais e marcos institucionais da cooperação brasileira. Rev Panam Salud Publica. 2012;32(6):444-50.

RESUMO O artigo contextualiza a emergência de uma política internacional para o Sistema Único de Saúde como agenda comum da Organização Pan-Americana de Saúde e do Ministério da Saúde brasileiro. Para tanto, foram explorados, ao longo do trabalho, dois eixos contextuais. No primeiro, discutem-se as relações expressas no trinômio desenvolvimento - cooperação saúde, de uma perspectiva internacional. No segundo, examina-se a evolução recente da política exterior brasileira, privilegiando o papel nela desempenhado pela Cooperação Sul-Sul e em torno da temática da saúde. Enfatiza-se a moldura contextual que define a cooperação internacional brasileira em parceria com a Organização Pan-Americana de Saúde, sobretudo no que tange à implementação de um termo de cooperação específico. Conclui-se que esse termo, nos marcos da Cooperação Sul-Sul, situa-se como um dos principais mecanismos institucionais estabelecidos com o propósito de realizar a cooperação técnica em saúde no cenário atual.

Palavras-chave Saúde mundial; cooperação técnica; cooperação internacional; Organização PanAmericana da Saúde; Brasil

A definição constitucional do Sistema Único de Saúde (SUS), em 1988, e sua regulamentação e implantação subsequentes são reveladoras dos êxitos e vicissitudes do movimento da reforma sanitária brasileira. São resultados expressivos, que se manifestam na institucionalização de um sistema de saúde de pretensões universais, o qual afirma a responsabilidade pública para com a saúde dos cidadãos, orientado por princípios e diretrizes, como os de integralidade, equi-

\footnotetext{
Observatório História e Saúde, Casa de Oswaldo Cruz, Fundação Oswaldo Cruz, Rio de Janeiro, Rio de Janeiro, Brasil. Enviar correspondência para Carlos Henrique Assunção Paiva, chapaiva@gmail.com

2 Organização Pan-Americana da Saúde, Brasilia, D.F., Brasil.
}

dade, descentralização, hierarquização e participação social. Seus resultados são positivos também no que concerne à prestação mesma dos serviços, expressos, por exemplo, na expansão da atenção primária à saúde, assim como na introdução de elementos inovadores nos processos de gestão.

Reconhece-se, todavia, que esses resultados são parciais. Para alguns, sob uma perspectiva mais crítica, a reforma sanitária brasileira teria se afastado de seu sentido político original, mais amplo e radical no que concerne ao modo de organização da sociedade brasileira e de suas formas coletivas de viver e adoecer (1). Para outros, por exemplo, ainda que em sua dimensão setorial restrita, a reforma sanitária, desde muito cedo, tem enfrentado obstáculos políticos e estruturais consideráveis - e ainda não transpostos $(2,3)$.

De um ponto de vista internacional, as conquistas da reforma sanitária brasileira, ainda que parciais, fazem do sistema de saúde do Brasil, uma experiência ímpar, sobretudo no contexto latino-americano. Sob a voga neoliberal, a região experimentou processos mais ou menos generalizados de privatização de serviços e de retração de políticas sociais. No campo da saúde, isso proporcionava forte crítica ao enquadramento da saúde, como direito e objeto de responsabilidade pública. Assim, ao defender seus princípios, a reforma da saúde, no Brasil, 
operou de forma contrária à maré liberalizante do período, e o SUS, público, universal e gratuito, apresentou-se como uma experiência em boa medida isolada em seus termos doutrinários.

Tendo em vista esse cenário de isolamento relativo e as resistências internas, no início do século XXI, o sanitarista Sérgio Arouca propôs um movimento de resistência e renovação da reforma sanitária. Arouca, então Secretário de Gestão Participativa do Ministério da Saúde, sugeria, entre outros aspectos, que o debate sobre a reforma brasileira fosse retomado também a partir de uma ótica internacional. Essa sua iniciativa resultou no esboço de um Programa de Difusão e Intercâmbio sobre Reforma Sanitária, de 2003, concebido como uma proposição conjunta do Ministério da Saúde e da Representação da Organização Pan-Americana da Saúde/Organização Mundial da Saúde (OPAS/OMS) no Brasil (4).

Para a Representação da OPAS/OMS, tratava-se de mobilizar a cooperação técnica internacional, de modo a promover reformas universalistas no setor da saúde, reafirmando a dimensão pública do direito à saúde, bem como estimulando laços de solidariedade e mecanismos para o intercâmbio de conhecimentos e experiências. Com esse desenho, a proposta correspondia às orientações da Oficina Central da OPAS, em Washington, em acordo com diretrizes da OMS. De fato, a partir de 2003, a OPAS passara a enfatizar o desenvolvimento de projetos de cooperação técnica centrados nos países, bem como o estímulo para que políticas de saúde internacional fossem melhor incorporadas às agendas dos Estados nacionais.

Ao Ministério da Saúde, haveria a possibilidade de divulgar a proposta doutrinária e organizacional de seu sistema de saúde, tendo em vista o reconhecimento internacional da experiência brasileira como uma política social modelar. Essa percepção se alinhava às orientações mais recentes da política externa brasileira, que conferia especial atenção à formação de blocos de aliança, nos marcos da Cooperação Sul-Sul, em particular com os países africanos de língua oficial portuguesa; com os países vizinhos latino-americanos; e com países da iniciativa IBAS (Índia-Brasil-África do Sul) (5).

Em 2006, nesse mesmo cenário, foi celebrado o Termo de Cooperação n. ${ }^{\circ} 41$
(TC-41) entre o Ministério da Saúde, a OPAS e a Fundação Oswaldo Cruz (Fiocruz), com interveniência da Secretaria de Gestão do Trabalho e da Educação em Saúde (SGTES). O TC-41 foi um dos principais mecanismos estabelecidos com o propósito de realizar o intercâmbio de experiências no contexto da Cooperação Sul-Sul em saúde.

Este artigo buscou contextualizar historicamente a emergência de uma política internacional do SUS como agenda comum da OPAS e do Ministério da Saúde brasileiro. Tratou dos elementos que contextualizam, em termos normativos e doutrinários, a cooperação entre o governo brasileiro e a OPAS, no âmbito da Cooperação Sul-Sul, como forma de compartilhar a experiência nacional na construção do SUS. Para tanto, foram explorados dois eixos contextuais. No primeiro, analisaram-se as relações expressas no trinômio desenvolvimento - cooperação - saúde, de uma perspectiva internacional. No segundo, foram examinados os processos institucionais que proporcionam as orientações mais imediatas para a Cooperação Sul-Sul em saúde, com a participação brasileira e da OPAS.

Na medida em que as iniciativas brasileiras de cooperação em saúde se intensificavam e passavam a compor o elenco das principais ações programáticas da saúde, um movimento similar realizava-se no âmbito da Representação da OPAS/OMS no Brasil. Nesse caso, pretendia-se definir um programa de ação, segundo as necessidades brasileiras e em sintonia com os esforços capitaneados pela OPAS. O TC-41, cujo contexto de surgimento é discutido, é abordado como expressão de um duplo movimento, que envolveu, de um lado, a OPAS, por meio de sua Representação no Brasil; e, de outro, o governo brasileiro, sobretudo por suas agências setoriais de saúde.

\section{Desenvolvimento, cooperação internacional e saúde}

A OPAS, constituída em 1902 como Repartição Sanitária Pan-Americana, foi uma das primeiras organizações intergovernamentais a serem estabelecidas. Sua criação foi parte do processo de instituição da saúde internacional como domínio da saúde pública e índice da crescente interdependência entre os povos, no contexto da expansão dos merca- dos capitalistas ao longo do século XIX. Na primeira metade século XX, a importância de sua atuação como organismo internacional especializado no contexto interamericano, ao lado de instituições privadas, como a Fundação Rockefeller, foi indiscutível, sobretudo em áreas como vigilância sanitária e controle de epidemias e endemias $(6,7)$

Reconhece-se, também, que foi, todavia, a partir de finais da Segunda Guerra Mundial que os organismos internacionais, como a Organização das Nações Unidas para a Educação, a Ciência e a Cultura (Unesco), o Banco Mundial e a OMS, entre outros, passariam a exercer maior protagonismo. Foi o início da era do desenvolvimento, compreendido tanto como um conjunto de valores e de recursos de conhecimento, técnicas e instituições - organizações internacionais, inclusive - que promovia a transformação do mundo, à feição dos países euronorte-americanos, quanto como uma arena para a qual convergiam demandas e expectativas das várias sociedades nacionais (8-10).

O debate em torno do desenvolvimento e dos meios para alcançá-lo foi sempre motivo de controvérsia. Em inícios da década de 1970, as versões mais otimistas acerca da capacidade transformadora da simples transferência de capitais e técnicas estavam em franca crise. Uma manifestação desse esgotamento pode ser medida pela tentativa de estabelecimento de uma Nova Ordem Econômica Internacional (NOEI), quando da realização da Assembleia Geral das Nações Unidas, de maio de 1974. Celebrada poucos meses depois do primeiro choque do petróleo, de finais de 1973, a declaração final da assembleia teve um claro tom terceiro-mundista, que, por sua vez, refletia o ambiente da chamada crise da hegemonia norte-americana, derivada de eventos como a derrota no Vietnã, o rompimento unilateral dos Acordos de Bretton Woods e a própria crise energética (11).

Simultaneamente, por delegação da mesma assembleia, era elaborado e discutido, no âmbito do Programa das Nações Unidas para o Desenvolvimento (PNUD), o informe de um grupo de trabalho sobre Cooperação Técnica entre Países em Desenvolvimento (12). Seus desdobramentos culminaram na elaboração e na aprovação, pela Assembleia Geral das Nações Unidas, do Plano de Buenos Aires, de 1978, cujo propósito 
central era promover a cooperação técnica entre países em desenvolvimento.

Esse contexto registrou a oposição e uma transição de enfoques entre as noções de "assistência" e de "cooperação técnica" como os termos adequados para definir as melhores relações entre países e instituições do mundo desenvolvido com aquele considerado como "em desenvolvimento"; dos países em desenvolvimento entre si e como princípio orientador para as práticas dos organismos internacionais. Assim, construiu-se a ideia de um percurso histórico, de uma evolução, nos modos de realização dessas relações: iniciou-se com as práticas filantrópicas, de caráter assistencial e paternalista; passou pelas relações de assistência técnica e se desenvolveu na direção de relações baseadas nas ideias de cooperação e de intercâmbio.

Esse percurso conceitual não deixou de se expressar nas formulações de organismos setoriais da saúde e, entre eles, da OPAS. Se forem tomados como exemplo as diretrizes formuladas na OPAS, em meados da década de 1970, para as atividades de cooperação no terreno da formação de recursos humanos em saúde, uma cooperação técnica ideal compreenderia: (i) a "rejeição" da ideia de "dependência" e o reforço da ideia de "autossuficiência", no campo dos países em desenvolvimento; (ii) a substituição da ideia de "transferência" por aquela de "criação e adaptação" e de "compartilhamento de experiências", em contextos similares; (iii) a participação do pessoal nacional e seu controle sobre as várias fases do processo de cooperação; e (iv) a adoção de modos de operação "flexíveis". Tal cooperação de novo tipo incluiria, também: (v) uma ampla mobilização dos "recursos locais"; (vi) a ação orientada a "objetivos e metas", ajustados às disponibilidades do país receptor; além da (vii) adoção de "tecnologias apropriadas" às necessidades e meios locais (13).

Essas prescrições, assim como os valores que lhes serviam de base, entretanto, se viram francamente restringidas pelas crises de finais dos anos 1970 e de início dos anos 1980, e pela emergência dos ajustes macroeconômicos de inspiração neoliberal, cujas implicações são bem conhecidas.

Quando as sociedades capitalistas ocidentais experimentaram um novo ciclo de crescimento, nas décadas de 1990, já sob a renovada hegemonia norte- americana que se seguiu ao colapso da experiência socialista no Leste Europeu, o conceito de desenvolvimento e as práticas de cooperação para o desenvolvimento já tinham sido substancialmente redefinidos. O Estado teve seu papel de protagonista do desenvolvimento reduzido e registrou-se o surgimento de uma constelação de atores não estatais, alguns deles crescentemente influentes. No mesmo passo, a cena internacional registrou uma perda de importância relativa das organizações multilaterais. Essa nova configuração implicou um enfraquecimento relativo da OMS, um processo que também afetou suas organizações regionais. Tal fragilidade expressava-se sob a forma de um orçamento cada vez mais dependente dos chamados fundos extraorçamentários, pelos quais países que já preferiam, de longa data, as formas de cooperação bilateral, o Banco Mundial e as fundações privadas eram capazes de atuar coordenadamente e definir sua própria política no interior da programação da OMS. Reconhece-se que essa tendência ocorreu em detrimento dos sistemas nacionais de saúde e das agências públicas, consideradas ineficazes, segundo os termos do credo neoliberal (14).

No decorrer da década de 1990 e dos primeiros anos da década seguinte, no contexto do Pós-Guerra Fria, a expectativa era de que um novo ciclo de expansão da cooperação pudesse ocorrer em um ambiente livre dos constrangimentos ideológicos da polarização Leste-Oeste. Essas expectativas logo se frustraram com a emergência de um novo intervencionismo relacionado à identificação das chamadas "novas ameaças" em regiões estratégicas aos olhos, sobretudo, do governo estadunidense. Esse movimento, importa registrar, ocorria com a crescente globalização dos fluxos financeiros, do comércio de mercadorias, das cadeias produtivas, das tecnologias da informação e da ampliação do alcance normativo de instituições como o Banco Mundial e o Fundo Monetário Internacional como pano de fundo.

A Agenda para a Paz das Nações Unidas, de 1992, refletia a percepção de que, em um quadro de complexidade crescente, a cooperação deveria promover a superação das múltiplas causas de instabilidade, frequentemente associadas a condições de marginalização políticosocial e fragilidade institucional (15). Nessas circunstâncias, foi introduzido o conceito de desenvolvimento humano (16), compreendido como um processo que ampliaria as condições de escolha e o desenvolvimento de capacidades dos indivíduos. Nessas mesmas circunstâncias, ao longo da década de 1990 e de inícios dos anos 2000, realizou-se um ciclo de conferências globais sobre temas como infância, meio ambiente, direitos humanos, população, igualdade de gênero, desenvolvimento urbano, etnias e combate à discriminação, e segurança. Sua culminância foi a Declaração do Milênio, aprovada pela Assembleia das Nações Unidas, em 2000 (17).

Adotada pelos 191 Estados membros das Nações Unidas, essa declaração estabeleceu os Objetivos do Milênio (ODM), fixados segundo prazos e indicadores quantitativos pré-estabelecidos que, ao longo do tempo, não deixaram de ser renovados em novas reuniões multilaterais e documentos.

O acompanhamento e a avaliação das ações de cooperação a partir dos ODM se expressaram, por exemplo, por meio do Consenso de Monterrey, de 2002, e da Declaração de Paris sobre Eficácia da Ajuda ao Desenvolvimento, de 2005. (18, 19) O consenso, resultado da Conferência Internacional sobre Financiamento e Desenvolvimento (Monterrey, México), estabeleceu que os países desenvolvidos ampliassem os fluxos de ajuda oficial $\mathrm{e}$ investimentos diretos aos países em desenvolvimento, além de recomendar a renegociação de suas dívidas externas e uma maior abertura dos mercados dos países ricos às exportações do Sul (18). A Declaração de Paris, seguindo o mesmo espírito, ao por em centralidade o conceito de "eficácia", chamava a atenção para a necessidade de uma maior coordenação das agências internacionais, de forma a evitar a duplicação de esforços; de definição de indicadores de desempenho; e de uma série de medidas de fortalecimento das capacidades institucionais para uma cooperação sustentável (19). Ambas as reuniões revelaram uma preocupação de reafirmar a necessidade de expandir o volume de recursos para Cooperação Norte-Sul; de corresponsabilizar prestadores e receptores da cooperação quanto à sua formatação e seus resultados; e de introduzir e aperfeiçoar mecanismos de coordenação, harmonização, acompanhamento e avaliação das iniciativas.

Em cada um desses níveis, sobrevieram tensões. Alguns dos principais 
países prestadores relutaram em dissociar a cooperação de seus interesses estritamente estratégicos ou mercantis imediatos, ao mesmo tempo em que condicionaram a cooperação à adesão a princípios como, por exemplo, o de livre-mercado e da democracia representativa. Nessa linha, as condicionantes em torno do fortalecimento institucional nos países receptores seriam ideologicamente orientadas (20).

Nesses novos tempos da cooperação, pode-se dizer, foram reeditadas algumas das preocupações que já se faziam presentes na cooperação técnica entre países em desenvolvimento, da década de 1970, como variante complementar da cooperação Norte-Sul. Tais preocupações diziam respeito à necessidade de estabelecer condições para uma maior paridade entre os países que compõem os polos da cooperação e de promover uma apropriação sustentada, pelos países receptores, dos elementos de conhecimento e tecnologia envolvidos no processo de cooperação. O contexto de início dos anos 2000 era, todavia, outro. As nacionalidades, a emancipação e soberania dos povos encontravam-se, então, em uma posição de muito menor destaque na equação do desenvolvimento (11)

A esse respeito e no tocante à OPAS, cumpre observar que, nos planos estratégicos de 2003-7 (21) e 2008-12 (22), foi nítida a preocupação em desenvolver sua capacidade de operar, a partir e com os países membros, tomando como ponto da partida a elaboração de estratégias de cooperação nacional. Da mesma forma, valorizou-se a cooperação técnica entre países, como forma de garantir maior sustentabilidade das intervenções e reforço da capacidade institucional de influir em questões transnacionais e globais. Em busca de maior impacto e melhor manejo de recursos nas ações de cooperação, enfatizou-se a necessidade de monitoramento e avaliação permanentes $(21,22)$. Na mesma direção, o Comitê Executivo da OPAS/OMS, reunido em junho de 2008, aprovou resolução específica sob o título Saúde e Relações Internacionais: Vinculações com o Desenvolvimento Sanitário Nacional. Segundo seus termos, os Estados da região deveriam promover a articulação entre saúde e relações exteriores, inclusive estabelecendo mecanismos de consulta entre as duas áreas de governo. Deveriam, ainda, reforçar as capacidades nacionais de gestão da cooperação, o que abarcava promover a inclusão dos temas da saúde na profissionalização dos diplomatas e, da mesma forma, dos temas das relações internacionais na formação em saúde (23).

A eclosão da crise financeira de 2008 e seus desdobramentos — ainda desconhecidos quanto à sua intensidade e duração - no tocante às contas nacionais e à disponibilidade de recursos para a implementação de políticas sociais, tornaram o cenário ainda mais desafiador. Reconheceu-se que as disponibilidades para a cooperação técnica internacional tenderam a se reduzir. Da mesma forma, as condições de vida, em países de economias agroexportadoras mais vulneráveis, estavam propensas a se deteriorar, aprofundando um processo iniciado pela globalização e pelos ajustes de inspiração liberal. Foi possível, por outro lado, que diferenças substanciais entre os países provedores, no que concerne ao impacto da crise e ao ritmo da retomada do crescimento, produzissem uma nova distribuição de poder e das responsabilidades no cenário da cooperação técnica internacional.

\section{O SUS internacional: o Ministério da Saúde, a Fiocruz e a cooperação OPAS-Brasil}

A assinatura e a implementação do TC-41, celebrado em 2006, entre o Ministério da Saúde, a Fiocruz e a OPAS, ocorreu em um contexto institucional tanto favorável quanto desafiador. De um lado, o Ministério da Saúde se orientava cada vez mais para um maior protagonismo internacional, aprofundando iniciativas junto aos países africanos e ao Mercosul, bem como estreitando seus vínculos com a pasta das relações exteriores. Sob a ótica da chancelaria, as iniciativas desenvolvidas no âmbito do Ministério da Saúde alinhavam-se às diretrizes da política externa brasileira. Estas, pelo menos desde o final do governo Fernando Henrique Cardoso (1995-2002), valorizavam a construção de coalizões estratégicas Sul-Sul.

Nos anos mais recentes, acumulam-se iniciativas do Ministério da Saúde no que tange à diplomacia da saúde e à cooperação técnica internacional em saúde e foi possível que se identificassem alguns episódios-chave desse processo de atualização da inserção brasileira na saúde internacional. Pôde-se indicar, de início, a participação do país nos debates e nas resoluções que, a partir da conclu- são da Rodada Uruguai, em 1994, tratou da proteção e da flexibilização dos direitos patentários sobre produtos farmacêuticos e suas implicações para a saúde pública. Essas difíceis tratativas, as quais não deixaram de envolver os diferentes interesses que se faziam representar na Organização Mundial do Comércio e na OMS, culminaram com a adoção, em 2008, da Resolução 21/61 da Assembleia Mundial da Saúde (24), que reconheceu a primazia das necessidades da saúde pública sobre os interesses comerciais.

Outro episódio referiu-se à expansão do horizonte da cooperação em saúde na América do Sul, quando os Chefes de Estado da União de Nações SulAmericanas (UNASUL), instituíram, em dezembro de 2008, o Conselho SulAmericano de Saúde. Sua instalação, em abril de 2009, reafirmou o processo de transformação da saúde em um tema central da agenda da integração regional.

No âmbito dos Países Africanos de Língua Oficial Portuguesa (PALOP), que incluem Estado-nacionais de formação relativamente recente e carentes de infraestrutura para o desenvolvimento, o papel do Ministério da Saúde brasileiro, a partir da segunda metade dos anos 1990, tem sido igualmente digno de nota. Operando frequentemente de forma triangular, em colaboração com a Agência de Cooperação Internacional do Japão, a Comunidade de Países de Língua Portuguesa (CPLP) e com outras agências de cooperação, o governo brasileiro realizou atividades que incluíam a qualificação, no Brasil, de profissionais daqueles países em áreas consideradas prioritárias, além do apoio direto à organização de serviços de saúde em Angola e Moçambique e de preparação pedagógica de cursos locais de pós-graduação na área de saúde pública (25).

A partir de 2005, passou-se a um outro patamar dessa relação de cooperação do governo brasileiro com os PALOP. Procurou-se dar suporte para estruturação das instituições de ensino e saúde pública situadas naqueles países, de modo que eles pudessem assumir a continuidade das atividades, tanto de treinamento de pessoal como de atendimento das necessidades assistenciais das populações. No final da década, as ações em desenvolvimento e em negociação, nos marcos de uma cooperação estruturante em saúde, envolviam, entre outras: a criação de escolas nacionais e programas de mestrado em saúde pública, a 
implantação de institutos e capacitação em saúde da mulher e da criança, a implantação de escolas e cursos de formação e capacitação técnica, o fortalecimento de instituições estratégicas para o desenvolvimento de sistemas nacionais de saúde, a implantação de uma unidade industrial farmacêutica, além do apoio à formulação de planos de cooperação estratégica em saúde (25-27).

A assinatura de um protocolo de intenções, em julho de 2005, entre os Ministérios da Saúde e das Relações Exteriores, formalizava as iniciativas de aproximação colaborativa entre as duas pastas. Em uma escala internacional, na Declaração de Oslo, assinada em março de 2007 (28), pelos ministros das relações exteriores do Brasil, Noruega, França, Indonésia, Senegal, África do Sul e Tailândia, assumia-se explicitamente a saúde como tema de política externa. Ao mesmo tempo, foram reafirmadas a necessidade da coordenação de esforços e a importância da saúde como tema da agenda do desenvolvimento.

As mesmas preocupações podem ser registradas quando da presença e do pronunciamento do Ministro das Relações Exteriores, Celso Amorim, na Assembleia Mundial da Saúde, em maio de 2007. Naquela oportunidade, o chanceler brasileiro reiterou a relevância da saúde como tema da diplomacia e mobilizou as disputas recentes em torno do licenciamento compulsório de patentes relativas a medicamentos antirretrovirais para destacar sua pertinência como tema relativo à soberania e à segurança dos países e de suas populações.

Por seu turno, a Fiocruz instrumentalizou-se para atuar como instância de formulação estratégica, coordenação e implementação de iniciativas em matéria de cooperação, com a implantação de um escritório regional africano, em 2008, localizado em Maputo, Moçambique, mediante acordo com a União Africana, e o estabelecimento, em 2009, do Centro de Relações Internacionais em Saúde (CRIS). Ao explicitar a orientação que adota para a condução de suas iniciativas internacionais, a Fiocruz tem afirmado seu compromisso com as estratégias de governo (29) e preconizado a necessidade da adoção de modelos alternativos de cooperação, alinhando-se às recomendações de documentos como a Declaração de Paris. ${ }^{3}$

\footnotetext{
3 Buss PM, Ferreira JR. Brazil Commitment to Global Health in South - South Cooperation. Rio de Janeiro: Fiocruz [2009]. [s.n.t. original inédito].
}

Quando o Ministério da Saúde lançou o Programa Mais Saúde Direito de Todos, apresentado como a estratégia de desenvolvimento da pasta para o período 2008-2011, e como segmento da saúde do Programa de Aceleração do Crescimento, instituído pelo governo de Luiz Inácio Lula da Silva, esses avanços na cooperação internacional receberam significativo destaque. O Mais Saúde baseava-se na perspectiva de que a saúde deve ser parte integrante de uma estratégia de desenvolvimento comprometida com o bem-estar e a equidade, como ambiente especialmente dinâmico, no que concerne à realização de investimentos, à inovação e à geração de empregos, renda e receitas. Ao fazê-lo, o programa definia a "cooperação entre os países" como um de seus sete eixos de trabalho. Nesse sentido, o programa assumiu como diretriz o fortalecimento da presença do Brasil no cenário internacional na área da saúde, sempre em estreita articulação com o Ministério das Relações Exteriores, assumindo como foco de atuação privilegiada os organismos e programas das Nações Unidas, os países da América do Sul (em especial os do Mercosul e da América Central), a CPLP e os demais países da África. Como medidas objetivas, o programa estabelecia, entre outras: o desenvolvimento de estruturas e dos sistemas de saúde dos países; a formação em larga escala de técnicos da área da saúde; o estabelecimento de programas de saúde na fronteira entre os países da América do Sul; e, por fim, a instituição de uma rede pan-amazônica de cooperação em ciência, tecnologia e inovação (30).

$\mathrm{Na}$ medida em que iniciativas desse tipo passavam a compor o elenco das principais ações programáticas da saúde, um movimento similar realizava-se no âmbito da Representação da OPAS/ OMS no país, em sintonia com os esforços capitaneados pela Oficina Central, no sentido de definir um programa de ação a partir das necessidades identificadas nos países. A celebração do TC-41 é expressão desse duplo movimento (31).

Desde início da década de 1970, a implantação de programas e projetos de interesse comum da OPAS e do governo brasileiro tem se dado sob a forma da celebração e operação de termos de cooperação. Sua implementação em campos como o desenvolvimento de recursos humanos, por exemplo, foi, muitas vezes, determinante para a própria cons- tituição, ao longo do tempo, de domínios de conhecimentos e práticas institucionais (31-33). O que o TC-41 possui como característica singular é que o conjunto das ações previstas tem por foco o estabelecimento de um Programa de Saúde Internacional (PSI), em colaboração com a pasta ministerial da saúde e a Fiocruz. Conforme sua programação, seriam desenvolvidas ações segundo a capacidade científica e técnica instalada na Fiocruz, principalmente, e nos demais setores do ministério, além das universidades. Fundamentalmente, o programa prevê atividades conjuntas nas áreas de pesquisa básica; saúde coletiva; produção de insumos; análise de políticas públicas; apoio às ações de ciência e tecnologia; experiências em desenvolvimento comunitário; controle de qualidade e risco ambiental; implementação de processos educativos inovadores; exploração de fontes de informação; comunicação social e história da saúde (34). Sua formatação orienta-se para a realização de operações de cooperação triangular, em que são partícipes o governo brasileiro, por meio do Ministério da Saúde e suas agências, a Representação da OPAS/ OMS no Brasil, e os países receptores e suas instituições. Os recursos disponíveis para a cooperação originam-se, principalmente, do orçamento regular do Ministério da Saúde.

Quando a Representação da OPAS/ OMS no Brasil elaborou, em 2007, sua Estratégia de Cooperação Técnica com a República Federativa do Brasil (20082012), ao explicitar a agenda pactuada com o país, foi dedicado um item programático à contribuição a ser propiciada para o fortalecimento da capacidade brasileira para cooperar com o desenvolvimento de sistemas de saúde na região das Américas e com os países de língua portuguesa da África. Na definição do "enfoque estratégico da cooperação", o documento definiu o apoio a "política de governo para a Cooperação Sul-Sul no campo da saúde" como um de seus eixos organizadores. Entre outros aspectos destacados, assinalou a necessidade da organização desempenhar as funções estratégicas de mediação e catalisação, contribuindo para os processos de formulação, execução e avaliação da cooperação triangular realizados entre o governo brasileiro, a OMS e os países receptores. Deve incluir, como parte de seu papel, o apoio à cooperação subregional com a participação brasileira, 
bem como a facilitação da articulação como as demais agências do Sistema das Nações Unidas (35).

\section{Considerações finais}

Os aspectos contextuais discutidos nas seções precedentes dizem respeito às relações entre desenvolvimento, saúde e cooperação, tal como experimentadas a partir da segunda metade do século $\mathrm{XX}$, e aos elementos institucionais mais imediatos relativos à formulação e à implementação dos principais mecanismos de cooperação entre o governo brasileiro e a OPAS, como forma de compartilhar a experiência nacional do SUS no âmbito da Cooperação Sul-Sul.

Sinalizou-se para um processo de crescente convergência - mas jamais desprovido de tensões e contradições — entre os assuntos da saúde e das relações exteriores. Essa convergência se converte, concretamente, na formulação de políticas e na implementação de iniciativas de cooperação em saúde, no contexto das alianças e das parcerias internacionais privilegiadas pela política externa brasileira.

No âmbito dos organismos internacionais, esse mesmo processo tem se baseado, de forma igualmente crescente, na ideia de que a cooperação para o desenvolvimento deve resultar em mecanismos e processos contínuos e sustentáveis, a exemplo do estabelecido na Declaração de Paris e em outros fóruns internacionais.

Ao definirem suas agendas de cooperação e seus princípios norteadores, o governo brasileiro e a OPAS integram esse mesmo movimento. Mais do que isso: revelam-se protagonistas no que tange à criação de mecanismos concretos de internacionalização dos assuntos da saúde. Dessa maneira, a forma como o governo do Brasil e a OPAS estabelecem seus arranjos institucionais, sem perder de vista as orientações definidas em fóruns internacionais, tem produzido, ao que tudo indica, um forte efeito estruturante para a organização do aparato institucional, das práticas e do acervo doutrinário da cooperação em saúde brasileira (26).

Em várias iniciativas de cooperação internacional em saúde, sobretudo naquelas que envolvem nações sul-americanas e africanas, o governo brasileiro vem desempenhando papel determinante. Quando as iniciativas de prestação de cooperação técnica pelo país se tornaram mais frequentes, o governo do Brasil e suas agências da saúde, com par- ticipação singular da Fiocruz e mediação da Representação da OPAS/OMS no Brasil, mobilizaram a expertise política e a capacidade técnico-científica do país, nos mais variados domínios, entre os quais, como visto, o desenvolvimento de plantas industriais de medicamentos e a criação de institutos nacionais de saúde; a implantação de cursos de pós-graduação em saúde pública; de graduação nas profissões de saúde; de escolas e redes de educação técnica; de redes de bancos de leite humano; de informação e comunicação em saúde - para citar apenas algumas das iniciativas desenvolvidas no continente africano.

Além disso, pode-se ponderar que as condições institucionais do cenário aqui parcialmente reconstruído sugerem que, quanto à formulação e à implementação das ações de cooperação propriamente ditas, o TC-41 tem viabilizado iniciativas em acordo ao que se poderia denominar a melhor tradição da cooperação técnica entre países em desenvolvimento e, ao mesmo tempo, atualizando-a pela incorporação das críticas mais recentes às formas e práticas da cooperação técnica internacional, inclusive no que concerne à sua real eficácia, eficiência e sustentabilidade.

\section{REFERÊNCIAS}

1. Paim J. Reforma sanitária brasileira: contribuição para a compreensão crítica. Salvador/ Rio de Janeiro: EDUFBA/Fiocruz; 2008.

2. Dain $S$. Os vários mundos do financiamento da Saúde no Brasil: uma tentativa de integração. Cien Saude Colet. 2007;12:1851-64.

3. Mendes A, Marques RM. O financiamento do SUS sob os "ventos" da financeirização. Cien Saude Colet. 2009;14(3):841-50.

4. Brasil. Ministério da Saúde. Organização Mundial da Saúde/Organização PanAmericana da Saúde. Programa de difusão e intercâmbio sobre a reforma sanitária (Prodirs). Brasília, DF: Ministério da Saúde/ Organização Pan-Americana da Saúde; 2003.

5. Labonté R, Gagnon M. Framing health and foreign policy: lessons for global health diplomacy. Global Health. 2010;6(14)2-19.

6. Lima NT. O Brasil e a Organização PanAmericana da Saúde: uma história de três dimensões. In: Finkelman J, organizador. Caminhos da Saúde Pública no Brasil. Rio de Janeiro: Fiocruz; 2002.

7. Cueto M. O valor da saúde: história da Organização Pan-Americana da Saúde. Rio de Janeiro: Fiocruz; 2007.
8. Escobar A. La invención del Tercer Mundo: construción e desconstrución del desarollo. Santa Fé de Bogotá: Grupo Editorial Norma; 1998.

9. Rist G. The history of development: from Western origins to global faith. Nova Deli: Academic Foudation; 2002.

10. Love J. A construção do Terceiro Mundo: teorias do subdesenvolvimento na Romênia e no Brasil. Rio de Janeiro: Paz e Terra; 1998.

11. Oliveira HA, Lessa ACL. Política internacional contemporânea. Mundo em transformação. São Paulo: Saraiva; 2006.

12. Organização das Nações Unidas (ONU). Conferência das Nações Unidas sobre Cooperação Técnica entre os Países em Desenvolvimento. Plano de ação de Buenos Aires. Buenos Aires/Argentina; 1978. [Citado 2012 Out. 27]. Disponível em: http://www.centroseda.org/ libro/Herramientas/Vinculos/Plan\%20Bue nos\%20Aires.pdf

13. Ferreira JR. Estrategias internacionales em educación médica: asistencia técnica y cooperation técnica. Educ Med Salud. 1976;10(4):335-44.

14. Brown T, Cueto M, Fee E. A transição da saúde pública "internacional" para "global" e a Organização Mundial da Saúde. Hist Cienc Saude Manguinhos. 2006;13(3):623-47.

15. Boutros-Ghali B. An Agenda for Peace: Preventive Diplomacy, Peacemaking and PeaceKeeping: Report of the Secretary-General Pursuant to the Statement Adopted by the Summit Meeting of the Security Council on 31 January 1992. New York: United Nations;1992.

16. United Nations Development Programme (UNDP). Human Development Report 1990. NY (USA): United Nations Developement Programme/Oxford University Press; 1990.

17. Organização das Nações Unidas (ONU). Declaração do Milênio. Cimeira do Milênio. Nova Iorque, EUA, 6-8 de setembro, 2000. [Citado 2012 Out. 27]. Disponível em: http:// www.unric.org/html/portuguese/uninfo/ DecdoMil.pdf

18. The United Nations (UN). Financing for development. Monterrey Consensus of the International Conference on Financing for Development. NY,USA: United Nations; 2003.

19. Organização para a Cooperação e Desenvolvimento Econômico (OCDE). Declaração de Paris sobre Eficácia da Ajuda ao Desenvolvimento. Lisboa, Portugual: Instituto Portu- 
guês de Apoio ao Desenvolvimento (IPAD); 2006.

20. Hirst M. La dimension política del mercosur: actores, politización y ideologia. Estudos Avançados. 1996;10(27):217-50.

21. Organização Pan-Americana da Saúde (OPAS). Plano Estratégico 2003-2007 da Repartição Sanitária Pan-Americana. Washington: OPAS; 2002.

22. Organização Pan-Americana da Saúde (OPAS)/Brasil. Estratégia de cooperação técnica da OPAS/OMS com a República Federativa do Brasil, 2008-2012. Brasília, DF: Organização Pan-Americana da Saúde; 2007.

23. Organização Pan-Americana da Saúde (OPAS). A saúde e as relações internacionais: seu vínculo com a gestão do desenvolvimento nacional da Saúde. [CD48/15 (Port.)6 de agosto de 2008]. Washington: OPAS; 2008.

24. World Health Assembly (WHA). Global strategy and plan of action on public health innovation and intellectual property. SixtyFirst World Health Assembly. 24 May 2008 [Cited 2012 Out. 27]. Available from: http:// apps.who.int/gb/ebwha/pdf_files/A61/ A61_R21-en.pdf
25. Agência Brasileira de Cooperação (ABC). A cooperação técnica brasileira em saúde. Via ABC. Brasília: Agência Brasileira de Cooperação; 2007.

26. Almeida C, Campos RP, Buss P, Ferreira JR, Fonseca LE. A concepção brasileira de "cooperação Sul-Sul estruturante em saúde". Reciis. 2010;4(1)25-35.

27. Buss PM, Ferreira JR. Diplomacia da saúde e cooperação Sul-Sul: as experiências da Unasul saúde e do Plano Estratégico de Cooperação em Saúde da Comunidade de Países de Língua Portuguesa (CPLP). Reciis. 2010;4(1):106-18.

28. Oslo Ministerial Declaration—global health: a pressing foreign policy issue of our time. Lancet. 2007;369(9570):1373-8.

29. Gadelha, P. Discurso de posse do presidente da Fiocruz, Paulo Gadelha. Rio de Janeiro: Fiocruz, 2009. [Citado 2012 Abr. 27]. Disponível em: http://www.fiocruz.br/ccs/cgi/ cgilua.exe $/$ sys $/$ start.htm?infoid $=2273 \&$ sid $=9$

30. Brasil. Ministério da Saúde. Mais saúde direito de todos 2008-2011. Brasília, DF: Ministério da Saúde; 2008.

31. Santana JP. Um Olhar sobre a Cooperação Sul-Sul em Saúde. Cien Saude Colet.
2010;0285. [Citado 2012 Abr. 27]. Disponível em: http://www.cienciaesaudecoletiva.com. br/artigos/artigo_int.php?id_artigo $=5255$

32. Paiva C, Pires-Alves F, Hochman G. A cooperação técnica OPAS-Brasil na formação de trabalhadores para a saúde (1973-1983). Cien Saude Colet. 2008;13(3):929-39.

33. Castro JL. Protagonismo silencioso: a presença da OPAS na formação de Recursos Humanos em Saúde no Brasil. Natal: Observatório RH-NESC UFRN/MS/OPAS/OMS; 2008.

34. Brasil. Ministério da Saúde. 41 Termo de cooperação e assistência técnica ao ajuste complementar celebrado entre a União Federal através do Ministério da Saúde e da Fundação Oswaldo Cruz e a Organização PanAmericana da Saúde/Organização Mundial da Saúde. Brasília, DF; 31 de dezembro de 2005.

35. Organização Pan-Americana da Saúde (OPAS). Propuesta del Plan Estratégico 20082012. Washington: OPAS; 2007.

Manuscrito recebido em 27 de maio de 2011. Aceito em versão revisada em 19 de março de 2012.

ABSTRACT The article contextualizes the emergence of an international policy for the Brazilian Unified Health System as the common agenda of the Pan American Health Organization (PAHO) and the Brazilian Ministry of Health. For this purpose, two contextual axes were explored throughout the work. The first discusses the explicit relationship between the development-cooperation-health triad from an international perspective. The second examines the recent evolution of Brazilian foreign policy, particularly with respect to the role it is playing in South-South cooperation on health matters. The contextual framework that defines Brazilian international cooperation with PAHO is emphasized, above all with regard to the implementation of a specific cooperation agreement. The article concludes that this agreement, within the framework of South-South cooperation, is one of the principal institutional mechanisms established to bring about technical cooperation in health in the current setting.

Key words World health; technical cooperation; international cooperation; Pan American Health Organization; Brazil. 